\title{
Homeland Security Science, Technology, Engineering, Mathematics Career Development Program Report
}

November 2009

Pacific Northwest

NATIONAL LABORATORY

Proudly Operated by Battelle Since 1965 


\title{
DISCLAIMER
}

This report was prepared as an account of work sponsored by an agency of the United States Government. Neither the United States Government nor any agency thereof, nor Battelle Memorial Institute, nor any of their employees, makes any warranty, express or implied, or assumes any legal liability or responsibility for the accuracy, completeness, or usefulness of any information, apparatus, product, or process disclosed, or represents that its use would not infringe privately owned rights. Reference herein to any specific commercial product, process, or service by trade name, trademark, manufacturer, or otherwise does not necessarily constitute or imply its endorsement, recommendation, or favoring by the United States Government or any agency thereof, or Battelle Memorial Institute. The views and opinions of authors expressed herein do not necessarily state or reflect those of the United States Government or any agency thereof.

\author{
PACIFIC NORTHWEST NATIONAL LABORATORY \\ operated by \\ BATTELLE \\ for the \\ UNITED STATES DEPARTMENT OF ENERGY \\ under Contract DE-AC05-76RL01830
}

Printed in the United States of America

Available to DOE and DOE contractors from the

Office of Scientific and Technical Information,

P.O. Box 62, Oak Ridge, TN 37831-0062;

ph: (865) 576-8401

fax: $(865)$ 576-5728

email: reports@adonis.osti.gov

\begin{abstract}
Available to the public from the National Technical Information Service, U.S. Department of Commerce, 5285 Port Royal Rd., Springfield, VA 22161 ph: (800) 553-6847 fax: (703) 605-6900 email: orders@ntis.fedworld.gov

online ordering: http://www.ntis.gov/ordering.htm
\end{abstract}




\section{Homeland Security Science, Technology, Engineering, Mathematics Career Development Program Report}

November 2009

Prepared for:

U.S. Department of Homeland Security Science

and Technology Directorate Office of university Programs

Pacific Northwest National Laboratory

Richland, Washington 99352 



\section{Executive Summary}

This report details the background, structure and mechanism to implement a working U.S. Department of Homeland Security (DHS) Homeland Security-Science, Technology, Engineering and Mathematics (HS-STEM) Career Development Program that meets the objectives of the DHS and DHS Science and Technology (S\&T) Directorate missions. The information is based on a narrative of the "Strategic Plan and Management Plan for HS-STEM Career Development" PowerPoint presentation given to the DHS Office of University Programs (OUP) management staff in July 2009. This report is presented as a deliverable related to the "Task Statement of Work for the HS-STEM Career Pipeline Program" (Task Order Agreement, IAA ref. HSHQDC-06-X-00486/P00002) that was performed October 2008 through September 2009.

Research results have indicated that federal career placement programs succeed by consistently making eight essential decisions that define their strategic goals and implementation plan. These eight essential decisions mold the basis for both the HS-STEM Career Development Program Strategic Plan and implementation-based Management Plan. These plans are presented as a path forward consideration as the existing DHS HS-STEM program continues to mature.

The U.S Department of Defense Information Assurance Program (DoD IASP) and the DHS National Cyber Security Division Scholarship for Service Program (SFSP) ${ }^{1}$ are both models of success for career development programs and are used as examples in this report.

The U.S. Department of Energy (DOE) national laboratories have played a valuable role in supporting DHS career development programs. Because of the practical experience gained through internship opportunities and relevant homeland security-related employment positions, research results indicated utilizing the DOE national laboratories should be used as potential pipelines for career placement.

\footnotetext{
${ }^{1}$ Brenda Oldfield (brenda.oldfield@dhs.gov) Director Education/Training (SFSP), DHS National Cyber Security Division.
} 



\section{Contents}

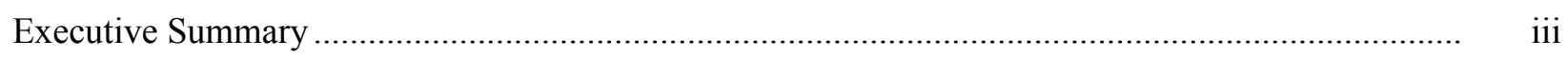

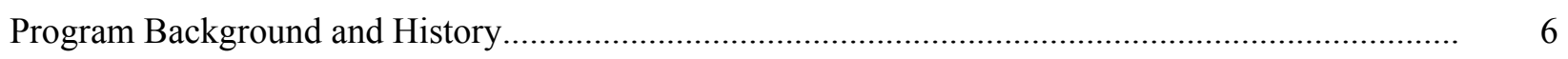

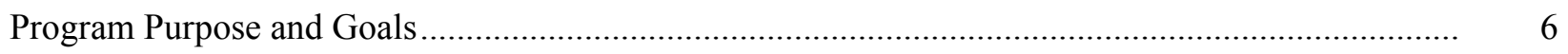

Program Development Methodology and Research .................................................................

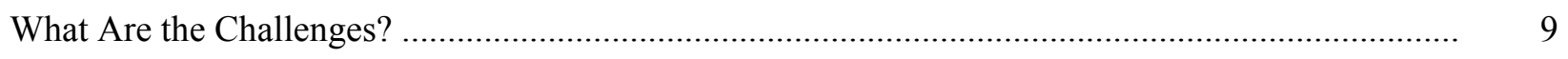

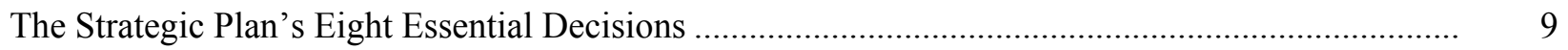

Models for Success Using the Eight Essential Decisions .............................................................. 10

HS-STEM Career Development Program Strategic Plan Development ........................................... 12

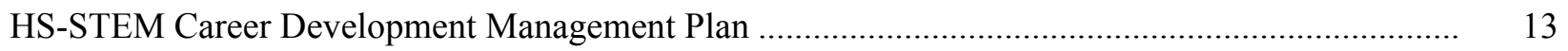

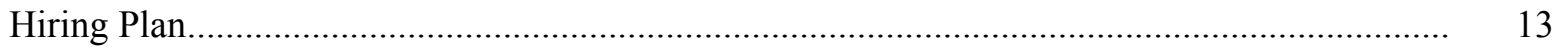

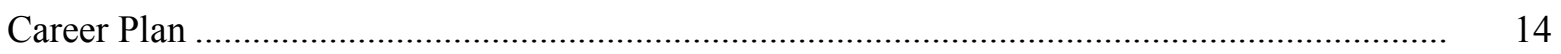

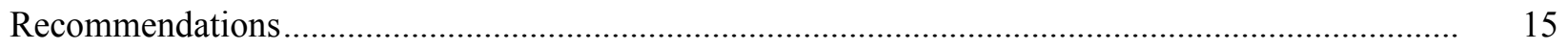

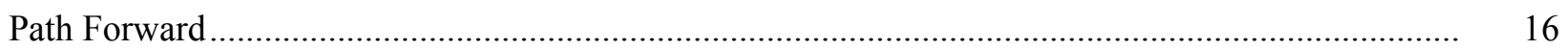

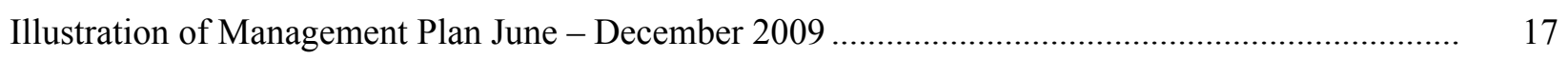

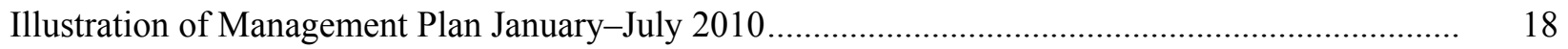

Appendix A - Outreach Activities.......................................................................................... A.1 


\section{Program Background and History}

The U.S. Department of Homeland Security (DHS) Office of University Programs (OUP) is furthering its commitment to the DHS mission by engaging the academic community to create learning and research environments in areas critical to homeland security. The overall mission of OUP is to stimulate, coordinate, leverage and use the unique intellectual capital in the academic community to address current and future homeland security challenges and educate the next generation workforce that DHS will need to protect the country into the foreseeable future.

Between 2007 and 2008, significant changes took place in both the OUP composition and organization. OUP started planning to establish career development pathways to identify and maintain the technically trained workforce that DHS needed to protect the country in the future. That effort was called the Homeland Security-Science, Technology, Engineering and Mathematics (HS-STEM) Career Development Program. The U.S. Department of Energy (DOE) national laboratories played a valuable role in supporting DHS through their acceptance of the DHS University Program Scholar and Fellows for summer internships. OUP believed the practical experience gained through these internship opportunities constituted one of the most critical elements of the DHS career pathways. OUP staff also anticipated that the DOE national laboratories could offer HS-STEM Career Development Program graduates with relevant homeland security-related positions.

In FY09, DHS initiated strategic planning to help shape and direct program partnerships between the OUP, DHS Centers of Excellence and the national laboratories to create pathways to careers in homeland security science and technology development. The initial component of the strategic planning was a study of the elements of the existing HS-STEM career development pathways. This study was conducted to identify opportunities to integrate these elements by improving coordination between education in academic disciplines and developing the professional experience in DHS science and technology development programs that would contribute to career choices and job placement in supporting homeland security.

\section{Program Purpose and Goals}

The Homeland Security Act of 2002 is the authorizing legislation for the DHS Science and Technology (S\&T) Directorate. The purpose of the S\&T Directorate is to support development and application of new technology for the DHS operational components. The S\&T Directorate was created and funded by Congress to identify, plan, coordinate, integrate and perform research, development, testing and evaluation (RDT\&E) to counter long-term, continuously evolving and technology-based threats (specifically, chemical, biological, radiological, nuclear and explosive CBRNE) ${ }^{1}$. This RDT\&E role encompasses the technology development needed by all of the DHS operational components. The S\&T Directorate requires an enduring HS-STEM workforce with the disciplinary education needed to manage (i.e., identify, plan, coordinate and integrate) and perform this homeland security RDT\&E mission. In essence, that HS-STEM workforce is the key to the success of the S\&T Directorate's longterm mission.

\footnotetext{
${ }^{1}$ HSA2002 Section $302(5)$
} 
Given the S\&T Directorate's mission as defined by Congress ${ }^{2}$ and the need for a specialized and enduring workforce to accomplish this mission, one can define a specific purpose for the DHS HS-STEM Career Development Program: The purpose of the DHS HS-STEM Career Development Program is to ensure an enduring workforce to manage and perform RDT\&E focused on continuing long-term, continuously evolving, technology-based threats.

Given the language in the S\&T Directorate's authorization, it is also clear that the HS-STEM Career Development Program is not responsible for the education of first responders. This function is the responsibility of state and local agencies. The DHS strategic plan states that "we will cooperate with our partners" in state and local agencies by giving grants. For example, the Federal Emergency Management Administration has a very large education program for first responders in cooperation with several hundred universities and community colleges.

Since the education of first responders is being attended by state and local agencies in cooperation with other DHS components, the HS-STEM program must focus its limited resources on its unique mission, which is to foster career development in science and technology areas that are vital for the success of the DHS RDT\&E mission. To this end, the HS-STEM Career Development Program provides scholarships for undergraduate and graduate students in key technical disciplines and identifies and supports internships and post doctoral training in DHS-related science and technology programs.

\section{Program Development Methodology and Research}

The HS-STEM work force required to support the S\&T Directorate's RDT\&E mission has unique characteristics, which that must be reflected in the development of a successful HS-STEM program. The HS-STEM workforce must be:

- Focused on the authorized mission of the S\&T Directorate. The purpose of building a RDT\&E workforce is to support the development and the application of new technology for the DHS operational components. Similarly, the DHS operational components have the responsibility of educating and training the specialized personnel that are needed to use technology to accomplish their missions.

- Experienced ${ }^{3}$ in those specific areas that the DHS research directorates are funding based on the requirements of the operational components.

- Enduring to support long-term RDT\&E in the specific technical areas required by DHS operational components.

- Agile because researchers will need to adapt technology ${ }^{4}$ to meet the new threats as terrorists shift their attack mode.

\footnotetext{
${ }^{2}$ Per: HSA2002 Sec. 302 (1), (2), (4), (7), 10, (11), (12), (13) and (14)

${ }^{3}$ Per: FAR 35.017 (2), (4) and FAR 17.503 (a), (a) (2), (b) (3)

${ }^{4}$ In a recent study (A Threat in Every Port, By LAWRENCE M. WEIN, Stanford University, CA, New York Times, Op-Ed, June 15, 2009) a professor at Stanford completed a statistical analysis of how many ways a terrorist can introduce CBRNE into the country and found 132 paths.
} 
- Multi-disciplinary. The RDT\&E needed to address the multiple terrorist threats is very complex and requires engineers and scientists of all types working together to develop the basic science and technology.

- The HS-STEM workforce must be led by RDT\&E managers who are experienced in homeland security RDT\&E and aware of its specialized program requirements. In particular, the DHS S\&T Directorate requires a specialized program management capability to organize and direct its specialized development programs.

A DHS HS-STEM Career Development Program plan, which has these characteristics, will have measurable metrics such as:

- A unique contribution to executing S\&T Directorate RDT\&E programs.

- A number of student participants who seek and gain employment with institutions that support DHS RDT\&E. There is no academic discipline that is uniquely "homeland security." The homeland security workforce includes many engineering disciplines working on interdisciplinary projects oriented towards homeland security missions. An HS-STEM career can only be defined by employment in an institution that conducts the enduring RDT\&E supporting the S\&T Directorate mission, such as S\&T Academic Centers of Excellence, DOE national laboratories or other Federally Funded Research and Development Centers FFRDCs. ${ }^{5}$

- Defined pathways for students to find the employment required by DHS RDT\&E. Without defined pathways, students will lack a clear direction to reach their HS-STEM goals.

- Relevant disciplinary education for students such as electrical engineering or mechanical engineering -the so-called "hard sciences." Those sciences lead to the most widely represented professions working on DHS RDT\&E. The DHS HS-STEM Career Development Program must include definitions of the relevant disciplines so universities will understand the purpose for the education they are providing.

- Experiential education for students in multi-disciplinary RDT\&E and with those employers that are aligned with the DHS S\&T Directorate's long-term goals.

- Clear RDT\&E employment expectations that will satisfy the HS-STEM service requirements. Student service requirements must define specific employment targets.

- Success in student placement with specific employers engaged in long-term S\&T Directorate development. Placement rates must be tracked to measure the success of the program. For example, the U.S. Department of Defense Information Assurance Program (DoD IASP) and the DHS Scholarship for Service Program both have a 90\% successful career placement rate with specified employers.

\footnotetext{
${ }^{5}$ Federal Acquisition Regulations (FAR) 35.017 pertain to how the government is required to use internal research and development (R\&D) laboratories. It defines the conditions that must be satisfied for the government to use its own resources, such as the national laboratories, rather than industry resources. It states there must be a unique government responsibility with characteristics that must be in place in order to put money into government research organizations, and in doing so, the government has the responsibility to assure that those research organizations have the technical talent needed. These are additional reasons the S\&T Directorate can fund education in the federal institutions used for RDT\&E
} 


\section{What Are the Challenges?}

Currently, placement of HS-STEM graduates in homeland security RDT\&T positions is a considerable challenge. Job postings that are homeland security-related have not been defined for the students. The DHS HS-STEM Career Development Program requests students to find a one-year entry level service position in their discipline and degree level and relate it to homeland security. This results in poor placement metrics because, currently, students cannot identify a homeland security-related position. At present, the one-year placement rate in any position that is even remotely related to homeland security is the only available metric. To address this issue, the program must include a process to identify targeted employers who are conducting enduring S\&T Directorate RDT\&E and who are also willing to take on a graduate for a one-year limited employment. The national laboratories, for example, have the staff for early evaluation of qualified candidates and could be brought into the limitedemployment process. The DHS HS-STEM Career Development Program strategic plan and corresponding program management plan addresses this placement challenge in more detail.

\section{The Strategic Plan's Eight Essential Decisions}

Federal career placement programs succeed by consistently making eight essential decisions that define their strategic goals and implementation plan. The first two essential decisions are:

1. Define clear federal ${ }^{6}$ career targets and,

2. Identify disciplines required by those target careers.

Both are necessary to define a clear goal for the DHS HS-STEM Career Development Program and a specific focus for the OUP education programs. Currently, the authorizing legislation for the S\&T Directorate does not include education per se. Only the development of careers, which are clearly supportive of, and necessary for, the enduring S\&T Directorate development programs, would justify an HS-STEM education program. UOP must be able to define the relevance of a HS-STEM "career program," and to do this the DHS S\&T Directorate RDT\&E programs must choose the RDT\&E career targets. Once a career target is defined, the appropriate disciplines should become obvious.

The choice of an appropriate career target is subject to an additional consideration. There is no authorization to spend S\&T, or even DHS funds, for education targeted towards industry careers. Industrial contractors are chosen because they have the appropriate staff to fulfill the goal of the contract. Industry recruits its RDT\&E employees from the general U.S. STEM workforce. Congress has authorized several federal agencies to support the education that maintains this national resource. DHS is not among them.

Once the first two essential decisions are made, six decisions remain to achieve an effective federal career development program:

3. Efficient mechanisms for program administration

4. Defined service responsibility

\footnotetext{
${ }^{6}$ Federal here includes federal government employment and employment in FFRDCs that are chartered to support federal programs.
} 
5. Clear Scholar, Fellow and Career Development Grantee Principal Investigator (CGD/PI) roles

6. Formal student contracts

7. Specific target employers

8. Student placement process.

Recommendations for these eight essential decisions as they relate to the HS-STEM Career Development Program are explained in detail in the Recommendations section below.

\section{Models for Success Using the Eight Essential Decisions}

The DoD IASP and the DHS Scholarship for Service Program (SFSP) are both models of success for focused government career development programs. The DoD IASP was established first and has been operating for many years. The DHS SFSP started in 2003, when DHS followed the DoD IASP model and adapted it to the differences between a civilian and military agency.

The following is an example of mapping the DoD IASP and/or DHS SFSP programs using the eight essential decisions model of success framework:

1. What is the specific federal career target?

DoD IASP careers were identified to include system network administration and operations, systems security engineering, information assurance systems and product acquisition, cryptography, and threat and vulnerability assessment. The DoD IASP concluded that the agency would have access to job candidates with related information assurance educations if there are good people in all these careers.

2. What are the disciplines needed for this career?

Disciplines identified to support DoD IASP scientific, technical and managerial disciplines included mathematics, biometrics, electrical and electronic engineering, computer science and engineering, software engineering, computer programming, computer support, data base administration, system analysis, operations research, information assurance and business management. Students interested in an information assurance career know what to study, and colleges know what curriculum to provide students.

The first two essential decisions define a clear goal and specific focus for implementation. Once these are decided, the six remaining essential decisions follow:

3. What is an efficient program administration approach?

DHS SFSP employs experienced federal agencies such as the National Science Foundation (NSF) and Office of Personal Management (OPM) to manage program administration. Both the DoD and DHS programs consulted with experienced federal agencies that knew how to implement these types of career programs. DHS chose to use an Interagency Agreement (IAA) with NSF to manage the fellowship applications process, review and selection and then use OPM for placement and contracts because a contract is in place between the students and OPM. In the DoD program, the contract is between the student and the grantee. Both approaches bring in a legal mechanism in case the student defaults on his/her obligation, in which case OPM turns it over to the U.S. Department of Treasury for collection. 
4. What is the post-graduation service responsibility?

In the DoD IASP program, for example, the fellowship application details the specific service responsibility that is stated up front before the student enters the program. Students that do not wish to perform the service responsibility do not submit the application.

5. What is the role of universities in career development?

Both programs established Academic Centers of Excellence, which are equivalent to the DHS S\&T Centers of Excellence. In both programs, the university applies for funding to set up the programs. NSF inspects these programs and certifies them as competent and authorized to recruit students. The student's PI manages their career development up to and including arranging interviews with perspective employers.

6. What is the contract for post-graduation service?

The DoD IASP uses the OPM applications for federal employment statement of employment conditions (Form OF 612). DHS SFSP uses a contract with OPM. Because DoD IASP identified all the agencies within the DoD that need candidates, the DoD IASP perspective student makes a federal application for federal employment. The application includes a statement that gives specific terms and conditions as well as information on the service requirements. The application is completed after the student has been awarded the internship. A student who cannot find an approved position must return the funding. The DHS contract with OPM is not quite as stringent as the DoD contract because OPM is a civilian agency.

7. What are the employers of the targeted careers?

The DoD IASP has identified specific DoD components and their career targets. For the DHS SFSP, a civilian government agency that wants career candidates is identified.

8. What is the placement process for graduates?

The DHS SFSP PI in the Academic Center of Excellence matches the student and agency by first selecting the applicant and then moving the application forward. DHS approves the agency choice and then OPM tracks the service. The DoD IASP hosts an agency "football draft" of applicants to allow an early employer match-when the application arrives at the agency, it is distributed to the other DoD agencies on the career list. The student is then advised of the agency choices.

Using these eight essential decisions has resulted in a $90 \%$ placement in target federal agencies for both the DoD and DHS programs. ${ }^{7}$ The HS-STEM Career Development Program Strategic Plan and Management Plan, discussed below, also use these eight essential decisions.

\footnotetext{
${ }^{7}$ Information Assurance Scholarship Program(IASP) DoD IASP Program Office, National Security Agency, 9800 Savage Road Fort George Mead, Maryland 20755 AskIASP@nsa.gov
} 


\section{HS-STEM Career Development Program Strategic Plan Development}

The following recommendations for developing the HS-STEM Career Development Program include eight career program decisions that map to the eight essential decisions with corresponding Strategic Plan objectives.

1. Clear Federal Career Target

Identify and engage as a partner specific DHS component RDT\&E that employ homeland securityrelated careers.

2. Target Careers Disciplines

Focus on the disciplines that serve the DHS RDT\&E programs. The objective is to identify, from the current and strategic programs, what disciplines DHS is funding and what resources those disciplines use or will use.

3. Program Administration

Decide whether to use administrative contractors or other agencies (e.g., OPM, NSF). If administrative contractors are used, the administrative task must be clarified, and desired output and outcome measures must be in the contract. If other agencies are used (i.e., NSF, OPM), an IAA must be in place.

\section{Service Responsibility}

Decide whether the responsibility will lie with the student, grantee PI or Other Federal Agency (OFA). If the student will be responsible, the program must specify responsibilities, reporting and tracking upfront in the application process. If the Grantee's PI will be responsible, specifications for grantee reporting, tracking and enforcing requirements must be included in the Federal Opportunity Announcement (FOA). If the OFA will handle the service responsibility, the OFA must develop an IAA with OPM for tracking and enforcement. The OFA can also monitor the post-graduation service.

\section{Clear Grantee and PI Roles}

Clear roles must be defined by those who manage the education programs. People familiar with homeland security careers and related technologies can guide student education and career decisions. The Grantee/PIs can follow two roles: 1) to manage the HS-STEM education, and 2) to manage the service placement. When managing education, mentoring and student reporting requirements must be included in the management contract. If the Grantee/PIs manage the service placement, there must be clearly defined employment targets and specific placement tasks in the management contract. Both the DoD and DHS career programs require quarterly reports from the Grantee on the student's progress. The students also have additional reporting requirements such as reporting grades. 


\section{Student Service Contract}

It must be clear who the contract is between - the student and the university or the student and OPM or DHS. If the contract is with the university, this needs to be stated in the Career Development Grant (CDG) along with a standard contract. For example, a contract between the DHS Scholars and Fellows student and DHS University Programs does not apply here because the program contract is with the program university. However, an incentive could be offered to the CDG university to track CDG service. If the contract is between the student and OPM or DHS, consult with OPM to define and develop a DHS Career Development Program contract or let OPM manage the contract through an IAA.

\section{Target Employers}

A legal contract must be set up between the HS-STEM Career Development Program and the target employers. By using the federal career targets, target employers would be the DHS RDT\&E performers used by DHS S\&T. A finite list of target DHS RDT\&E venues must be identified. Most of the RDT\&E funds $S \& T$ distributes to all national laboratories go to about 13 organizations, which is a reasonable number with which to negotiate when setting up internships, jobs or limited-term appointments.

\section{Student Placement}

Responsibility for placing a student must be clarified among the student, Grantee/PI or University Programs. If it will be the student's responsibility, the program must specify the student's requirements regarding their job search. In the DoD and DHS programs, the student must report their job search activities semi-annually. If it will be the Grantee/PI's responsibility, the contracting FOA must require the Grantee/PI to place the student for service. The University Program or OPM CDG Administrator must approve the employer choice. Active pre-graduation employer matching must be required in the FOA. Both the DoD and DHS programs require their Academic Centers of Excellence to talk to and visit the identified prospective employers. If it will be the University Program responsibility, OUP and the DHS Office of National Laboratories must liaise and negotiate agreements with target RDT\&E venues. The recommended approach is to place the responsibility with the Grantee/PI through the contract.

\section{HS-STEM Career Development Management Plan}

The previous essential decisions also used to define the Management Plan for the HS-STEM Career Development Program, which is divided into two focus areas, the hiring plan and the career plan.

\section{Hiring Plan}

The DOE national laboratories are used as a model for the following because this is a common hiring structure within the laboratories.

- The laboratory's homeland security program manager directs the RDT\&E staff alignments to its customers. That individual may or may not manage homeland security programs exclusively, but the programs they manage have needs similar to that of homeland security. 
- Every year the program managers estimate the funding from their customers yearly, then estimate the required staffing and provide that information to the laboratory technical group manager who hires and manages the staff.

- The technical group manager prepares job descriptions based on the ability to provide staff required by the program manager's requests.

- This process is followed for laboratory recruiting at all job levels. However, for the HS-STEM Career Development Program, it would be difficult for students to identify all jobs that are homeland security-related.

- Once the laboratory receives job applications, all HS-STEM graduate applications are put into an application process including, but not identifying, those funded through DHS University Programs.

- The technical group manager interviews and selects applicants based on the best match to position requirements.

\section{Career Plan}

The Career Plan addresses the job application issues for the HS-STEM Career Development Program.

- The first step is to keep in contact with the national laboratories to identify entry-level jobs with the most DHS S\&T work. DHS S\&T must define what they mean by "HS-STEM jobs" to clarify what jobs are identified as "homeland security." DHS S\&T can create review committees from the DHS S\&T R\&D divisions to identify homeland security entry-level jobs posted on the laboratory websites. Once jobs are identified, applicants could review the web postings.

- An HS-STEM "placement toolkit" could be developed and sent to the scholarship program manager (which could be NSF, OPM, or Oakridge Institute for Science Education) or the CDG administrators. The CGD PI initially recommends students, knows the students and is responsible for facilitating early interview for students.

- Early Service for Scholarship interviews can be arranged with the national laboratories' technical group managers. Homeland security applicants must be distinguished early to avoid being lost in the general STEM graduate application pool. By knowing the goals and careers through the contract and by using the placement toolkit, students can be selected and encouraged to apply.

- Include outreach to Minority Serving Institutes (MSI)s

- Manage the Career Development Grant award.

- Act as a career mentor to the awardees, and monitor and report on their progress.

- Work with the internship employers to get potential internships.

- Monitor the student's service requirement. CDGs or OPM can monitor the students.

- After an internship, the technical group manager may be willing to take the student on as a permanent staff member. An alternative would be to negotiate with the laboratories to set aside a number of "limited term appointments." For example, the laboratory would agree to take on a designated number of HS-STEM graduates for one year. 
The above recommendations create a clear career path for developing permanent staff professionals that have an education oriented towards homeland security. Qualified candidates can be funneled into the staff pool of the research organizations that perform DHS S\&T work.

HS-STEM education for career placement is a complex undertaking, but there are really only two management challenges - clear definitions and consistent communication. The system is very complex. Everyone must understand the purpose of the system and their role in it.

On the education side, there must be:

- Service requirement, which is communicate to the students

- HS-STEM-related jobs definition communicated to the students.

- Definition of the HS-STEM careers communicated to all the universities and CDGs

- CDGs and universities' definition of the appropriate disciplines to support the careers and communication to the students.

Regarding career placement:

- All the RDT\&E providers must communicate the available positions.

- HS-STEM positions must be defined and communicated to the students.

- Entry level positions and the level - graduate, $\mathrm{PhD}$ students - are identified and successful communications are facilitated.

By addressing the management challenges of HS-STEM careers, an HS-STEM education process would then be consistent with the purpose of DHS S\&T as authorized (HSA2002). It could:

- Unify the disparate elements of the education program from the MSIs through college and graduate schools to STEM career placement

- Provide an outstanding metric of successful placements to maintain support for the education program

- Give specific value for federal dollars spent on HS-STEM education

- Produce experts in this area of research

- Reduce the management load once participants understand their goals and roles.

\section{Recommendations}

The following recommendations are based on the research results for implementing the HS-STEM Career Development Program.

1. Empower the OUP staff to integrate the strategic plan for career development with the strategic plan for education. By integrating the education strategic plan with the career development plan, a clear purpose could be defined. 
2. OUP staff must evaluate and choose from the remaining alternatives, evaluating the pros and cons of what can be done and what is manageable.

3. Implement the resulting program management plan to achieve the strategic plan's goals and objectives. The plan can be put into operation by the OUP staff if it has clarity and goals.

4. Shepherd the current OUP education participants toward the career management goal by emphasizing clear definitions and consistent communication. Once the new strategic plan is in place, it will probably be two or three years before new solicitations can be prepared with the new strategic plan details in place. This should include talking with the people that will be bidding before the solicitations go out.

\section{Path Forward}

This Management Plan is presented in terms of the eight management decisions that correspond to each of the essential management decisions. The first essential decision - the Career Federal Target forms the starting point of this plan and requires working with OPM, considering other alternatives and analyzing career decisions. This plan is organized by tasks and sub-tasks. 


\section{Illustration of Management Plan June - December 2009}

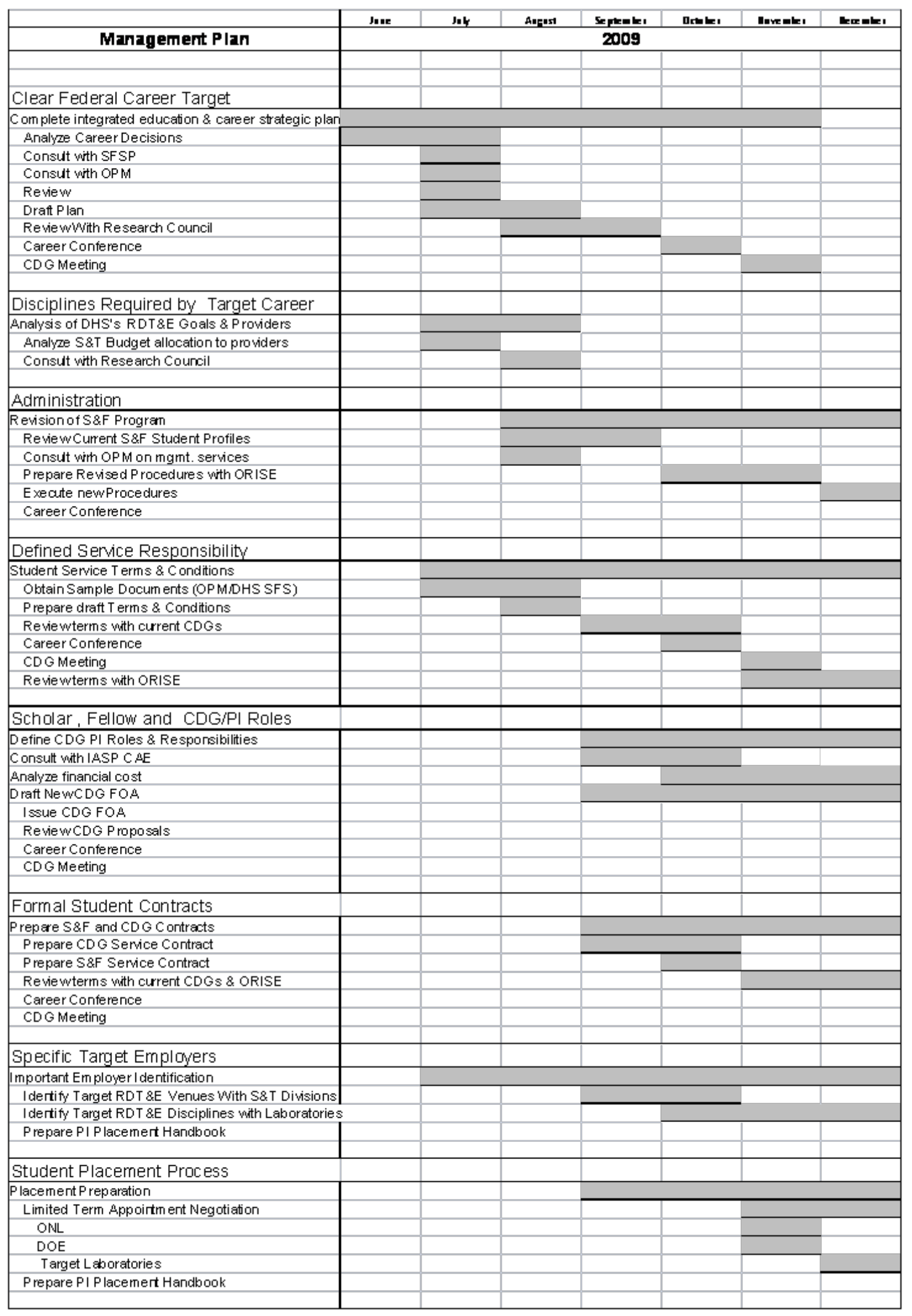




\section{Illustration of Management Plan January-July 2010}

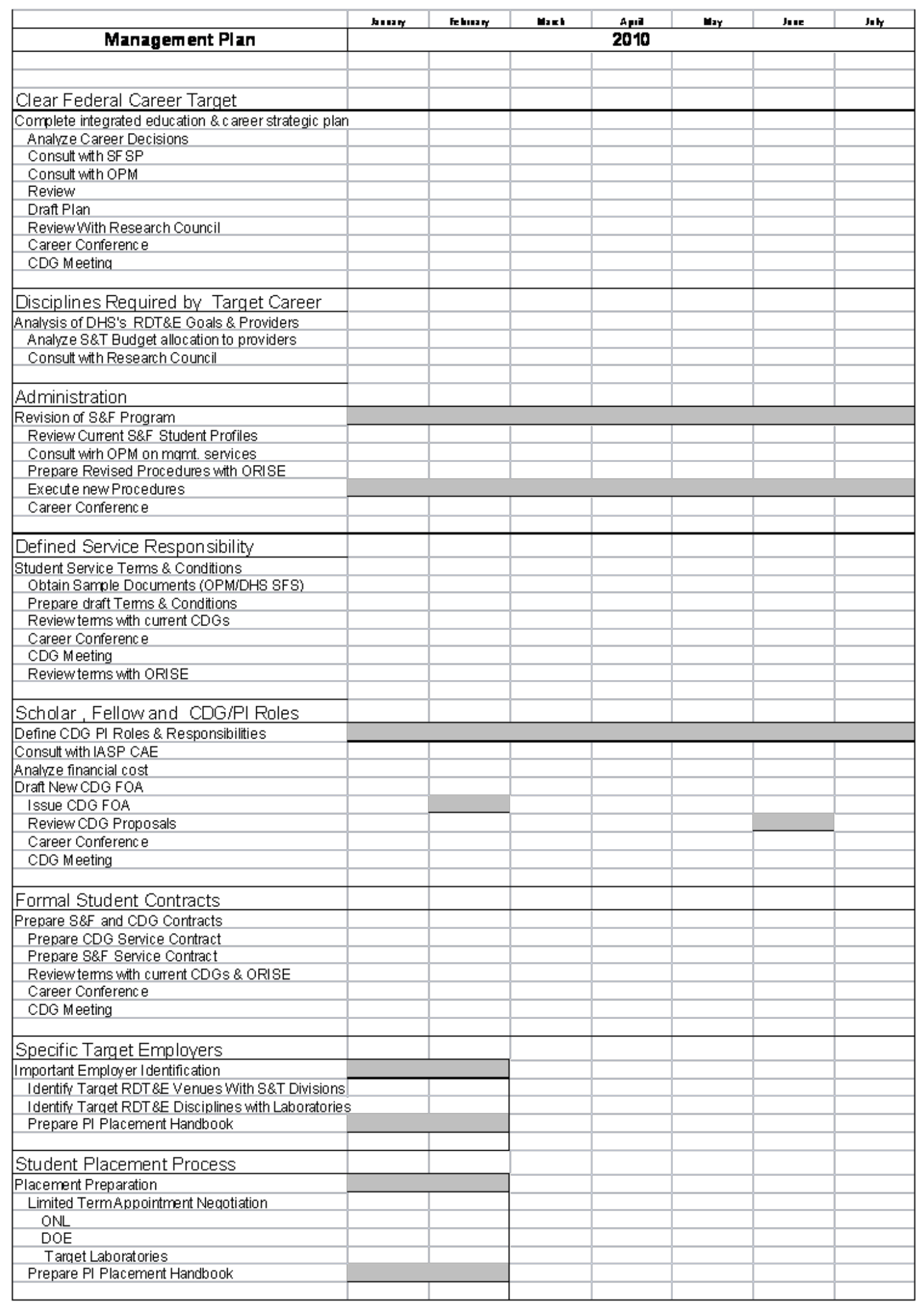


Appendix A

\section{Outreach Activities}





\section{Appendix A}

\section{Outreach Activities}

\begin{tabular}{|c|c|}
\hline HS-STEM Career Development Program Project Deliverables & Document \\
\hline $\begin{array}{l}2009 \text { Strategic Plan and Management Plan for the HS-STEM Career Development } \\
\text { Program PowerPoint presentation }\end{array}$ & $\begin{array}{l}\text { Career Placement } \\
\text { Plan-Print Version.pdf }\end{array}$ \\
\hline $\begin{array}{l}\text { Timeline for the HS-STEM Career Development Program development and } \\
\text { implementation }\end{array}$ & Timeline.pdf \\
\hline UP Career pathway extended to MSIs - presentation to Desiree Linson on Nov. 25, 2008 & $\begin{array}{l}\text { Outline of HS-STEM } \\
\text { Career Development }\end{array}$ \\
\hline Outline of the HS-STEM Career Development Program - Nov. 19, 2008 & $\begin{array}{l}\text { Outline of HS-STEM } \\
\text { Career Development }\end{array}$ \\
\hline Meetings and Presentations & Document \\
\hline $\begin{array}{l}\text { UP Staff Strategic and Management Plan for a UP Career Program presentation - June } \\
22,2009\end{array}$ & $\begin{array}{l}\text { Career Placement } \\
\text { Plan-UP Version. pdf }\end{array}$ \\
\hline Career Pathway presentation to Stephanie Willett - June 15, 2009 & $\begin{array}{l}\text { Career Placement } \\
\text { Plan-Stephanie.pdf }\end{array}$ \\
\hline $\begin{array}{l}\text { "Homeland Security - Science, Technology, Engineering, and Mathematics (HS-STEM) } \\
\text { Workforce Development" presentation, DHS S\&T Directorate Research Council } \\
\text { Meeting - March 23, } 2009\end{array}$ & $\begin{array}{l}\text { Understanding the } \\
\text { HS-STEM System-V2-I }\end{array}$ \\
\hline $\begin{array}{l}\text { DOE Laboratory Homeland Security Director's meeting in Seattle, WA presentation } \\
\text { January 29, } 2009\end{array}$ & $\begin{array}{l}\text { Outline of HS-STEM } \\
\text { Career Development }\end{array}$ \\
\hline $\begin{array}{l}\text { DOE Office of Workforce Development for Teachers and Scientists meeting - January } \\
2009\end{array}$ & $\begin{array}{c}\text { DOE Office of } \\
\text { Science Contacts.pdf }\end{array}$ \\
\hline
\end{tabular}




\begin{tabular}{l|c|c|c|c|}
\hline \multicolumn{1}{c}{ Meetings and Presentations } & Document \\
\hline Presentation to Matt Clarke, Desiree Linson and Stephanie Willett on the proposed path \\
for developing a HS-STEM Career Development Program - January 2009
\end{tabular}

\section{Papers, Articles}

DHS Office of National Laboratories Newsletter article - March 2009

DHS University Programs "Pipeline” newsletter article - August 2009

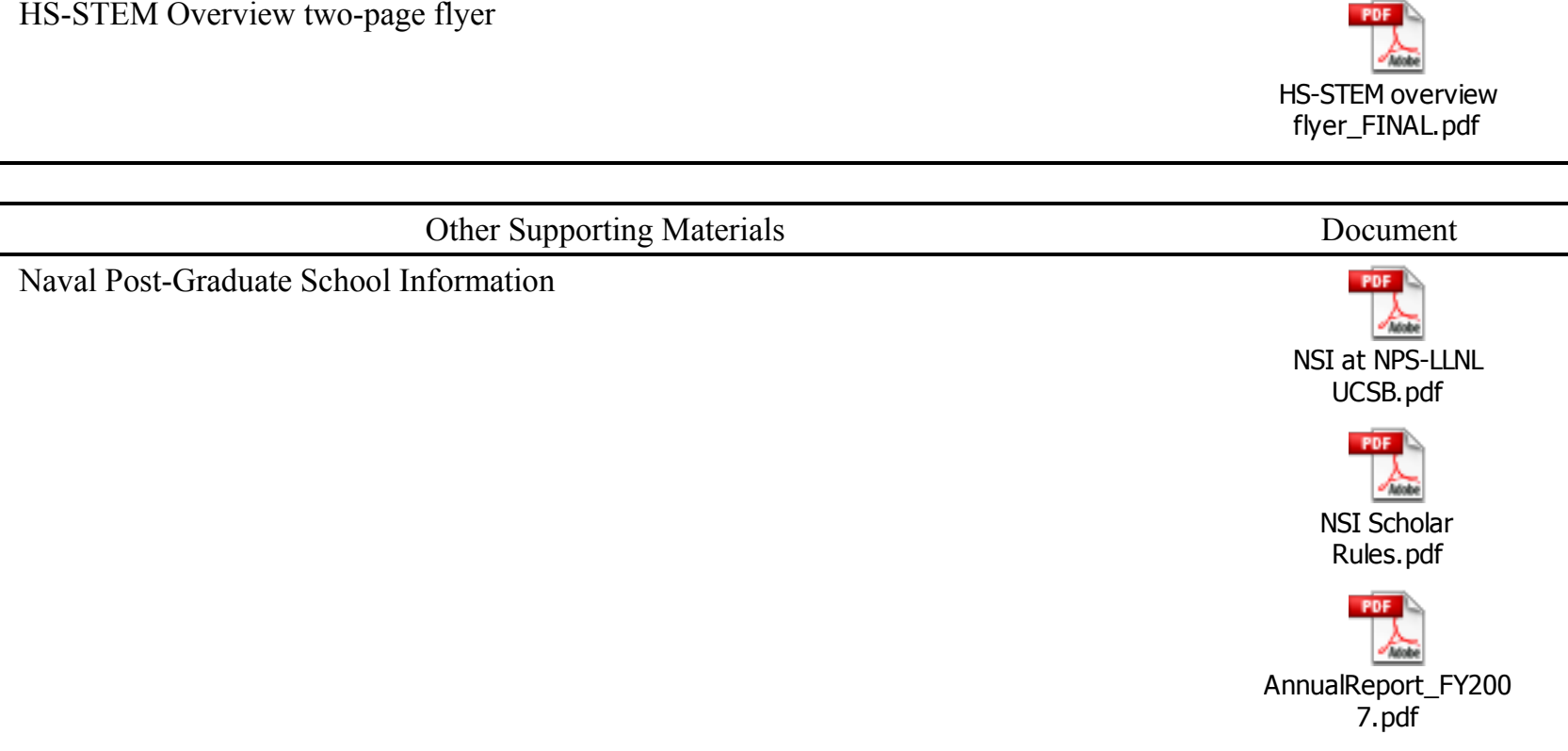




\begin{tabular}{l}
\hline \multicolumn{1}{c}{ Other Supporting Materials } \\
\hline Department of Energy Office of Science College Plan Guide
\end{tabular}

